https://dx.doi.org/10.4314/ijs.v23i1.8

Ife Journal of Science vol. 23, no. 1 (2021)

\title{
PESTICIDE RESIDUES IN SELECTED VEGETABLES FROM GOMBE MARKETS, GOMBE STATE, NIGERIA: ASSESSING THE HEALTH IMPACT
}

\author{
${ }^{1}$ Maigari, A.U., ${ }^{2 *}$ Sulaiman, M.B., ${ }^{3}$ Buhari, M., ${ }^{3}$ Abdullahi, A.O. \\ 'Department of Chemical Sciences, Federal University Kashere, Gombe State, Nigeria. \\ ${ }^{2}$ Department of Pure and Industrial Chemistry, University of Nigeria, Nsukka, Enugu State, Nigeria. \\ ${ }^{3}$ Department of Chemistry, Gombe University, Gombe State, Nigeria. \\ "Corresponding author. E-mail: sulaimanmuhammadbashir@gmail.com; mohammad.sulaiman.pg01935@unn.edu.ng \\ (Received: $20^{\text {th }}$ October, 2020; Accepted: $13^{\text {th }}$ February, 2021)
}

\begin{abstract}
The study determined the content of pesticide residues in vegetables (cabbage, lettuce, calyces, and tiger nut), obtained from markets in Gombe, Nigeria. Health risk parameters were also determined to evaluate the health risk associated with their consumption. A total of 72 samples (cabbage, lettuce, calyces and tiger nut) were analyzed using high performance liquid chromatography with UV/VIS Detector (HPLC-UV/VIS). A total of 18 pesticide residues were detected: nine organochlorines (OCs), five organophosphates (OPs), and four pyrethroids (PYs). The residual contents of nine OCs ranged from 0.00 to $0.098 \mu \mathrm{g} / \mathrm{kg}$ and found in $61.87 \%$, $60.99 \%, 63.69 \%$, and $63.89 \%$ of cabbage, lettuce, calyces and tiger nut samples respectively, five OPs with concentrations ranging from 0.00 to $0.043 \mu \mathrm{g} / \mathrm{kg}$ were found in $22.69 \%, 21.89 \%, 19.49 \%$ and $22.21 \%$ of cabbage, lettuce, calyces and tiger nut samples respectively. In similar order, four PYs with concentrations that ranged from 0.00 to $0.046 \mu \mathrm{g} / \mathrm{kg}$ were found in $15.44 \%, 17.04 \%, 16.82 \%$ and $13.89 \%$ of the vegetables. The mean estimated daily intake of pesticides in the studied samples was lower than that of acceptable daily intakes. The hazard index obtained was less than one, indicating no probable adverse health effect on both children and adult consumers. However, monitoring and continuous stringent regulation should be imposed with regard to the usage of pesticides in vegetables, and other food stuff for public health protection.
\end{abstract}

Keywords: Hazard Index, Health risk, Nut, Pesticide residues, Vegetables

\section{INTRODUCTION}

Pesticides are substances, normally used in current agricultural activities for the protection of crops from various pests and diseases (Guler et al., 2010; Ahoudi et al., 2018), a small amount of pesticides remains on a crop after harvesting or storage as pesticide residues (Ononamadu et al., 2019). A large number of these pesticides like organochlorines (OCs), organophosphates (OPs) etc., have been applied in agriculture to improve agricultural productions which lead to a dramatic increase in its application over the years (Donkor et al., 2016; Han et al., 2017). Farmers in diverse regions across the globe use different variety of pesticides such as organochlorines (OCs), organophosphates (OPs), pyrethroid (PYs), etc (Shakhaoat et al., 2013). OCs, OPs, and PYs are three most widely used pesticides in most developing countries (Seyedeh et al., 2019), to boost agricultural productivity to supply an adequate food for the increasing human population (Liu etal., 2016).

Vegetable is one of a major part of the human diet providing dietary requirements of nutrients
(Ovaskainen et al., 2008; Vincent et al., 2018). They are widely used for culinary purposes (Ononamadu et al., 2019). Tomato, onions, Lettuce and cabbage are the most consumed vegetables in Nigeria. The pest control practices in vegetable production in Nigeria involve applications of highly toxic pesticides which could result in pesticide contamination of the agricultural produce (Adeleye et al., 2019). Some of the vegetables are usually consumed raw with little or no processing. The presence of pesticides residue in vegetables could affect its nutritional quality as well as causing adverse health effects (Adeleye et al., 2019). The consequence of wide usage of these pesticides in agricultural production leads to increase in health risks and environmental degradation (Yasir et al, 2020). The World Health Organization estimates about three million cases of pesticide residue poisoning yearly with approximately 220,000 deaths worldwide (WHO, 1990; Shakhaoat et al., 2013). The preponderance of death cases were recorded in developing countries due to their poor agricultural practices (Shakhaoat et al., 2013; Kumari and John, 2019). The health implication of pesticide 
residues in foods has been reported in several types of research (Jara and Winter, 2019). Pesticide residues in vegetables constitute a possible risk to consumers and a number of reports have been documented (Charan et al., 2010; Angioni et al., 2011; Sinha et al., 2012; Shakhaoat et al., 2013; Sapbamrer and Hongsibsong, 2014; Lozowicka et al., 2015; Donkor et al., 2016; Lehmann et al., 2017; Ahoudi et al., 2018; Adeleye et al., 2019; Yasir et al., 2020).

The quantity of reports focusing on pesticide residues were less for nuts than vegetables and fruits (Liu et al., 2016). There are few reports regarding pesticide residue in nuts, even though nuts are rich in minerals, vitamins, fiber and a higher unsaturated fatty acid (Grosso et al., 2015). The majority of pesticides are absorbed in the lipid medium of the nuts due to their hydrophobic nature and passed to the consumers (Liu et al., 2016). On the other hand, their dietary consumption has been reported to be related to decline in occurrence of cardiovascular diseases, tumors, etc. (Grosso et al., 2015). It is therefore essential to evaluate the risks related with dietary exposure to pesticide residues for awareness, in order to protect the health of consumers (Shoiful et al., 2013). Therefore, this research work is aimed at determining the levels of organochlorines, organophosphates, and pyrethroids residues in cabbage, lettuce, calyces, and tiger nut and the corresponding human health risk assessment due to their intake.

\section{MATERIALS AND METHODS}

\section{Study Area}

The area of study is Gombe metropolis, capital of Gombe state and lies between latitude $10^{\circ} 17^{\prime} 05.88^{\prime \prime} \mathrm{N}$ and $11^{\circ} 10^{\prime} 36.78^{\prime \prime} \mathrm{E}$ with an area coverage of about $52 \mathrm{~km}^{2}$. The study area is tropical climate with two distinct rainy and dry seasons (May-October) and (November-April) respectively. Other weather conditions are: 28.5 ${ }^{\circ} \mathrm{C}$ annual temperature, $903 \mathrm{~mm}$ mean precipitation and relative humidity ranges from 15 to $20 \%$ in December and 70 to $80 \%$ in August (Sulaiman and Maigari, 2016). Figure 1 shows the map of Gombe town and the sampling locations.

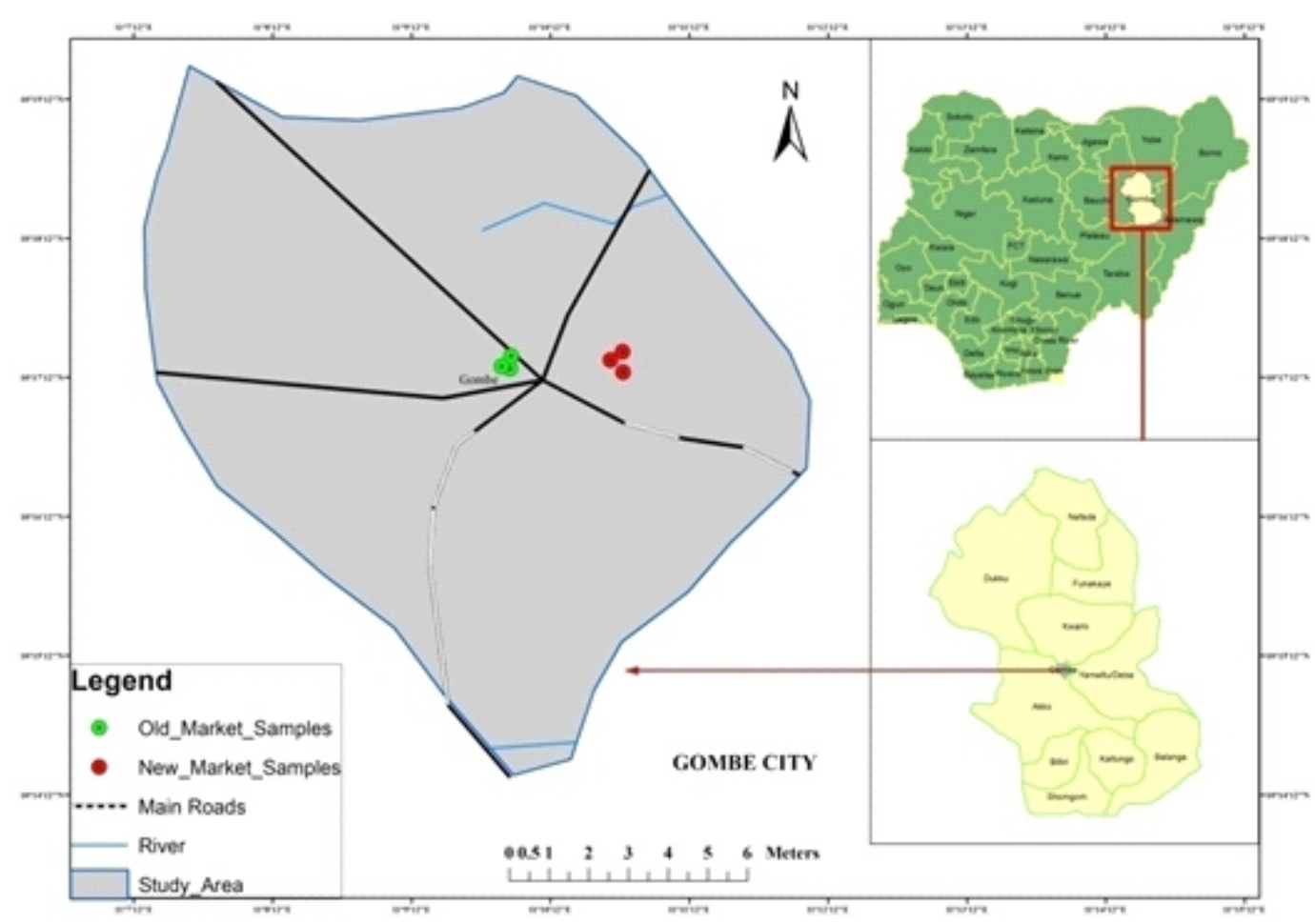

Figure 1: A map showing the sampling locations in Gombe, Nigeria 


\section{Sample Collection}

A total of 72 samples (cabbage, lettuce, calyces and tiger nut; 18 each) were purchased from markets (new and old) for the analysis of pesticide residues. The study was carried out from March 2019 to February 2020. The purchased samples were placed in poly bags and were taking to the laboratory and stored in a refrigerator at $4{ }^{\circ} \mathrm{C}$ until the analysis. Sampling and preparation protocol was as described by Kumari and John (2019).

\section{Chemicals and Reagents}

An analytical standard of pesticides, i.e mixed standard of organochlorines (OCs), organophosphates (OPs), and pyrethroids (PYs) with 99.9\% purity; acetonitrile (HPLC grade), activated charcoal, anhydrous sodium sulphate, sodium chloride, and ethyl acetate were purchased from Merck, Germany.

\section{Sample Preparation and Extraction}

Vegetables: $50 \mathrm{~g}$ of each homogenized vegetable was placed in a beaker and $50 \mathrm{ml}$ of 3:1:1 ethyl acetate, hexane, and sodium chloride was added and were then centrifuged for $5 \mathrm{~min}$. The organic extracts were concentrated to $5 \mathrm{ml}$ with a water bath at $45^{\circ} \mathrm{C}$ using a vacuum rotary evaporator. The sample cleaning was done with a glass column having a $5 \mathrm{ml}$ layer of anhydrous sodium sulphate and $10 \mathrm{~g}$ activated charcoal to eradicate any residual components that may possibly interfere with the high performance liquid chromatographic analysis and was further redissolved in $5 \mathrm{ml}$ of acetonitrile for the HPLC analysis.

Nut: $50 \mathrm{~g}$ of nut was ground to powder with mortar and pestle, $5.0 \mathrm{~g}$ of powdered nut sample was added to $50 \mathrm{ml}$ of 3:1:1 ethylacetate, hexane, and sodium chloride. The extract was concentrated to $5 \mathrm{ml}$ using a vacuum rotary evaporator at $45{ }^{\circ} \mathrm{C}$. The sample cleaning was done with a glass column having a $5 \mathrm{ml}$ layer of anhydrous sodium sulphate and $10 \mathrm{~g}$ activated charcoal to eradicate any residual components that may possibly interfere with the high performance liquid chromatographic analysis and was further re-dissolved in $5 \mathrm{ml}$ of acetonitrile for the HPLC analysis.

\section{Instrumental Analysis}

The determination of the residues was carried out by injecting $1 \mu$ l of the $1.0 \mathrm{~cm}^{3}$ purified extract into the injection port of HPLC (Buck scientific (BLC10/11- model, Las Vegas USA), equipped with UV/VIS Detector set at 200-700 nm. The mobile phase with an initial composition consisting of $7 \%(\mathrm{v} / \mathrm{v})$ solvent A $(100 \%$ acetonitrile), and $93 \%$ of $20 \mathrm{mM} \mathrm{KH} \mathrm{PO}_{4}$ at a flow rate of $1 \mathrm{ml} / \mathrm{min}$ was maintained for seven min. Solvent A was then added initially, $10 \%$ at 20 min, then increased to $15 \%$ at $25 \mathrm{~min}$, then $20 \%$ at $30 \mathrm{~min}$, and finally $25 \%$ at $45 \mathrm{~min}$ to $70 \mathrm{~min}$. The programming was sustained in the isocratic mode in the following order: $40 \% \mathrm{~A}$ at 70.1 to $75.0 \mathrm{~min}$ and $7 \% \mathrm{~A}$ at 75.1 to $90.1 \mathrm{~min}$. The column temperature was maintained at $30{ }^{\circ} \mathrm{C}$, all detections were made at $338 \mathrm{~nm}$.

\section{Quality Control and Quality Assurance}

The samples spiked with $0.15 \mathrm{mg} / \mathrm{kg}$ and 0.01 $\mathrm{mg} / \mathrm{kg}$ of pesticide standards were prepared some minutes before the extraction of pesticides from the samples and analyzed for the pesticides in order to check the instrument for recovery and efficiency. The limit of detection (LOD) ranged from 0.0011 to $0.02(\mu \mathrm{g} / \mathrm{kg})$ and the recoveries ranged from 96 to $99 \%$ for spiked samples, this indicate the precision and reproducibility of the method adopted for extraction of the pesticide.

\section{Statistical Data Analysis}

The data obtained from the analysis were statistically analyzed using SPSS version 20, for windows. Analysis of variance was used to determine the variation among means at a value of less than $(\mathrm{P}<0.05)$ level of significance.

\section{Risk Assessment}

The risk assessment model recommended by the USEPA was used to estimate the health risk related with pesticide residues, as reported by Vincent et al. (2018). 


\section{Estimated Daily Intake (EDI)}

The estimated daily intake was determined using the United States Environmental Protection Agency's guidelines (USEPA).

$\mathrm{EDI}=\frac{\mathrm{C}_{i} \times \mathrm{C}_{r}}{\mathrm{BW}}$

Where: EDI $\equiv$ estimated daily intake, $\mathrm{C}_{\mathrm{i}} \equiv$ concentration of pesticide residue $(\mu \mathrm{g} / \mathrm{kg}), \mathrm{C}_{\mathrm{r}} \equiv$ consumption rate of food ( $\mathrm{kg} / \mathrm{day})$, and $\mathrm{BW}$ is the average body weight $(\mathrm{kg})$. Consumption rate elsewhere was used together with USEPA body weight (USEPA, 1989; USEPA, 1996; Oyeyiola et al., 2017).

\section{Hazard Index (HI)}

Hazard Index (HI) was determined by dividing the estimated daily intake (EDI) and the acceptable daily intake (ADI).

$\mathrm{HI}=\frac{\mathrm{EDI}}{\mathrm{ADI}}$

Where: $\mathrm{HI} \equiv$ Hazard index for non-carcinogenic health risk, EDI $\equiv$ estimated daily intake and ADI $\equiv$ acceptable daily intake. Acceptable daily intake reported elsewhere was used (Wang et al., 2011).
When $\mathrm{HI}$ is greater than one, it means that lifetime consumption of measured vegetables could be capable of causing health effects (Vincent $e t$ al., 2018).

\section{RESULT AND DISCUSSION Content of OCs in Samples}

The summary of the content of OCs in the samples is presented in table 1. Residues of aldrin and alpha benzene hexachloride $(\mathrm{BCH})$ were detected in all the samples studied, aldrin ranged from 0.069 to $0.083 \mu \mathrm{g} / \mathrm{kg}$ in cabbage, 0.036 to $0.073 \mu \mathrm{g} / \mathrm{kg}$ in lettuce, 0.045 to $0.055 \mu \mathrm{g} / \mathrm{kg}$ in calyces and 0.055 to $0.058 \mu \mathrm{g} / \mathrm{kg}$ in tiger nut, while alpha $\mathrm{BCH}$ ranged from 0.089 to $0.098 \mu \mathrm{g} / \mathrm{kg}, 0.075$ to $0.077 \mu \mathrm{g} / \mathrm{kg}$, 0.042 to $0.050 \mu \mathrm{g} / \mathrm{kg}$ and $0.049 \mu \mathrm{g} / \mathrm{kg}$ in similar order. Aldrin and alpha $\mathrm{BCH}$ detected were below acceptable daily intakes (ADIs). There was a significant difference at $(\mathrm{P}<0.05)$ between aldrin residues in calyces, cabbage, and lettuce samples, significant differences in alpha $\mathrm{BCH}$ residues were also obtained in calyces and tiger nut samples from new and old markets. Aldrin and alpha $\mathrm{BCH}$ residues in this study were below the values reported in a similar study, in which residues of aldrin and alpha $\mathrm{BCH}$ ranges from 0.7 to $1.96 \mu \mathrm{g} / \mathrm{kg}$ and 0.58 to $0.82 \mu \mathrm{g} / \mathrm{kg}$, respectively (Wang et al., 2011). 


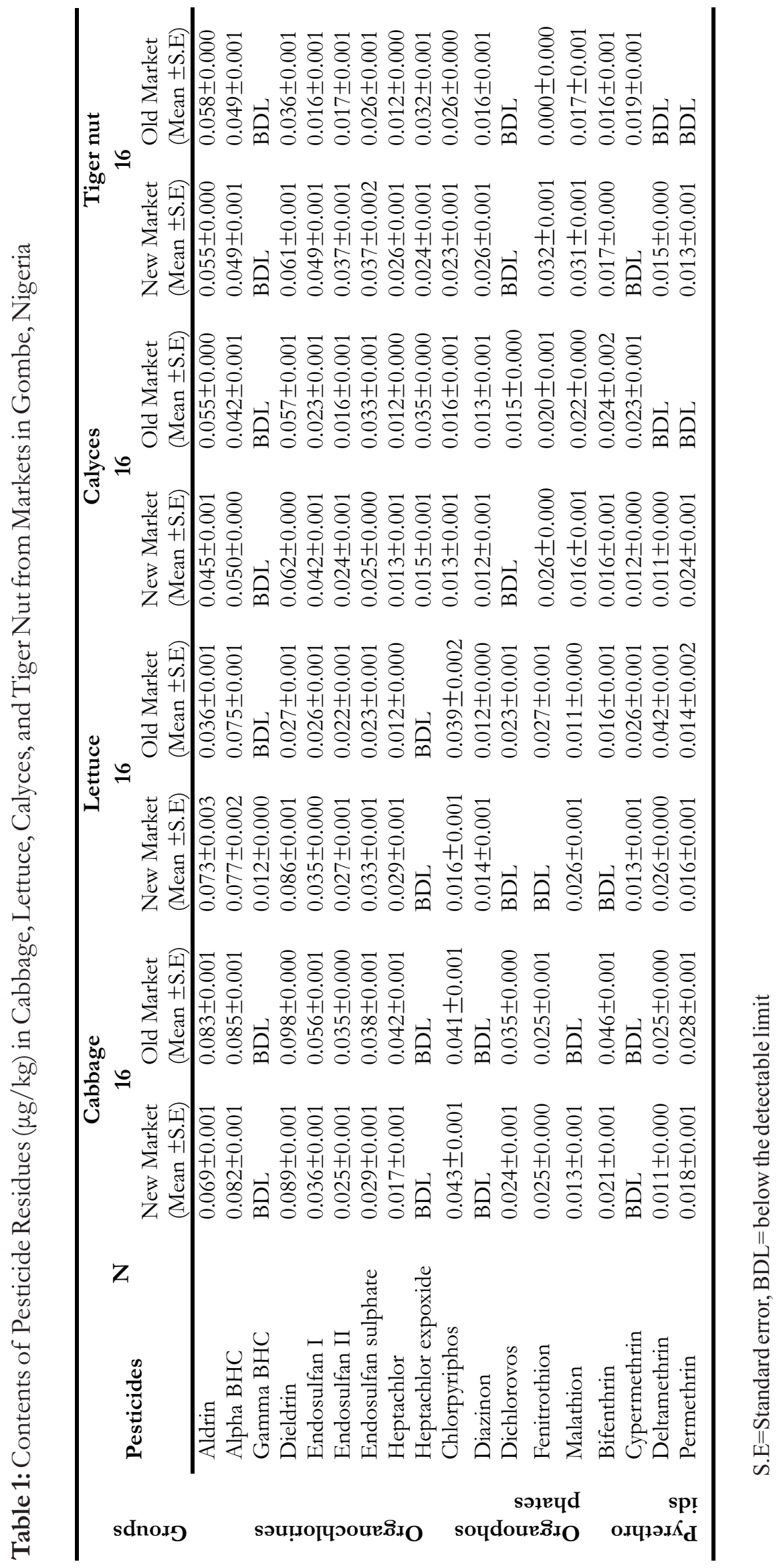


A study on pesticide residues on vegetables in Ghana also reported a higher level $(22.66 \mu \mathrm{g} / \mathrm{kg})$ of aldrin in lettuce (Vincent et al., 2018) which is above the residues obtained in this study. Gamma $\mathrm{BHC}$ was detected in lettuce from a new market in this present study, with residual content of 0.60 $\mu \mathrm{g} / \mathrm{kg}$, and below the detectable limit in other samples. Dieldrin ranged from 0.027 to 0.098 $\mu \mathrm{g} / \mathrm{kg}$, endosulfan I, endosulfan II and endosulfan sulphate ranged from 0.016 to 0.056 $\mu \mathrm{g} / \mathrm{kg}, 0.016$ to $0.037 \mu \mathrm{g} / \mathrm{kg}$ and 0.023 to 0.038 $\mu \mathrm{g} / \mathrm{kg}$ respectively, while heptachlor ranged from 0.012 to $0.042 \mu \mathrm{g} / \mathrm{kg}$. Heptachlor epoxide was detected in calyces with residues in the range of 0.015 to $0.035 \mu \mathrm{g} / \mathrm{kg}$ and 0.024 to $0.032 \mu \mathrm{g} / \mathrm{kg}$ in tiger nut from both markets, the residue of heptachlor detected in both calyces and nut were lower than the values set by European Union maximum residue level (EU MRL). There was a significant difference at $\mathrm{P}<0.05$ between gamma BHC, dieldrin, endosulfan I, endosulfan II, endosulfan sulphate, heptachlor, heptachlor epoxide residues in calyces, cabbage, lettuce tiger nut samples from new and old markets. The detection frequencies for the OCs were aldrin $(17.56 \%)$, alpha BHC (18.85\%), gamma BHC $(3.56 \%)$, dieldrin $(19.11 \%)$, endosulfan I $(9.04 \%)$, endosulfan II $(7.52 \%)$, endosulfan sulphate $(10.48 \%)$, heptachlor $(6.04 \%)$ and heptachlor epoxide $(7.85 \%)$. The occurrence order of the detection of OCs in the samples were tiger nut $(63.89 \%)>$ calyses $(63.69 \%)>$ cabbage $(61.87 \%)$ $>$ lettuce $(60.99 \%)$.

\section{Content of OPs in Samples}

The summary of the content of OPs in the vegetable samples is presented in table 1 . Chlorpyrifos was the pesticide detected in all the samples with the residual concentration ranging from 0.013 to $0.43 \mu \mathrm{g} / \mathrm{kg}$. A number of researchers had also reported the presence chlorpyrifos residues in vegetables (Charan et al., 2010; Chen et al., 2011; Sinha et al., 2012; Swarnam and Velmurugan, 2013; Sapbamrer and Hongsibsong, 2014; Silipunyo et al., 2016; Lehmann et al., 2017; Kumari and John, 2019). The presences of chlorpyrifos in all samples could be as a result of its persistence and accumulation characteristics (Angioni et al, 2011). The value of chlorpyrifos recorded in vegetable samples in the present study was lower than the values reported in earlier studies, which ranged from 0.006 to $0.024 \mathrm{mg} / \mathrm{kg}$ (Silipunyo et al., 2016) and 1.42 to $2.01 \mathrm{mg} / \mathrm{kg}$ (Ononamadu et al, 2019); values reported in the nut was $34.9 \mathrm{mgkg}^{-1}$ (Liu 2016). The contents of diazinon, dichlorovos, fenitrothion, and malathion, ranged from below detectable limit (BDL) to $0.026 \mu \mathrm{g} / \mathrm{kg}$, BDL to $0.35 \mu \mathrm{g} / \mathrm{kg}$, BDL to $0.32 \mu \mathrm{g} / \mathrm{kg}$, and BDL to 0.026 $\mu \mathrm{g} / \mathrm{kg}$ respectively. The following pesticides were below detectable limits: diazinon in cabbage, dichlorovos in lettuce and calyces from new market samples, and tiger nut from both markets; fenitrothion in lettuce from new market and malathion in cabbage from old market samples. The residual content of OPs in all samples was lower than the maximum residue level set by EU/EPA. There was a significant difference at $\mathrm{P}$ $<0.05$ between chlorpyrifos residues in calyces and lettuce samples. Significant differences in fenitrothion residues were also recorded in calyces, lettuce and tiger nut samples from new and old markets. The frequencies of detection of the OPs were $26.27 \%$ chlorpyriphos, $15.01 \%$ diazinon, $23.47 \%$ dichlorovos, $18.77 \%$ fenitrothion, and $16.46 \%$ malathion. The occurrence order of the detection of OPs in the samples were cabbage $(22.69 \%)>$ tiger nut $(22.21 \%)>$ lettuce $(21.89 \%)>$ calyces $(19.49 \%)$.

\section{Content of PYs in Samples}

The summary of the content of PYs in the vegetable samples is presented in table 1. PYs are effective for controlling various pests and with low toxicity to non-target organisms (Liu et al., 2016). The contents of PYs ranged from below detectable limit (BDL) to $0.046 \mu \mathrm{g} / \mathrm{kg}$ in cabbage, BDL to $0.042 \mu \mathrm{g} / \mathrm{kg}$ in lettuce, BDL to 0.024 $\mu \mathrm{g} / \mathrm{kg}$ in calyces, and BDL to $0.010 \mu \mathrm{g} / \mathrm{kg}$ in tiger nut. The residue content of PYs in samples was higher in cabbage compare to lettuce, calyces and nut samples, particularly the content of bifenthrin $(0.046 \mu \mathrm{g} / \mathrm{kg})$ in one of the cabbage samples. However, the residual content of PYs was lower than the maximum residue level set by EU/EPA. There is a significant difference at $\mathrm{P}<0.05$ between bifenthrin residues in calyces, lettuce and cabbage samples. Significant differences in permethrin contents were also recorded in calyces, cabbage and tiger nut samples from new and old markets. The frequencies of detection of the PYs were $31.71 \%$ for bifenthrin, $18.90 \%$ for 
cypermethrin, $26.42 \%$ for deltamethrin, and $22.97 \%$ for permethrin). The occurrence order of the detection of PYs in the samples were lettuce $(17.04 \%)>$ calyces $(16.82 \%)>$ cabbage $(15.44 \%)$ $>$ tiger nut $(13.89 \%)$.

\section{Health Risk Assessment}

The risk assessment was based on the content pesticide residues in cabbage, lettuce, calyces, and tiger nut samples. The predicted health risk summary of the pesticide residues in the samples is presented in table 2. The hazard indexes represent the hazardous effect of the substance to consumers of the contaminated vegetables (Ftsum and Abraha, 2018; Sulaiman etal., 2019). If the value of hazard index is less than one, consumers of the investigated food stuff are safe from possible health risks (Yang and Liu, 2012). The hazard index of OCs residues ranged from 5.00E-01 to 7.64E-05 for children and 9.91E-02 to $9.31 \mathrm{E}-06$ for adults, while OPs residues ranged from 2.30E-02 to 8.90E-06 for children and 4.16E-03 to $9.70 \mathrm{E}-06$ for adults and PYs residues ranged from $2.40 \mathrm{E}-02$ to $9.90 \mathrm{E}-05$ for children and 6.84E-07 for adults. The hazard index of OPs residues obtained in this present study was lower than values (1.68) reported in nut from Iran (Seyedeh et al., 2019). The highest health index was found in OCs for aldrin (5.00E-01) for children (in calyces). However, hazard indexes estimated for the samples were far less than one, this suggests that the consumption of vegetable and nut samples would pose no adverse health effect on both children and adults consumers. 
Table 2: Health Risk Assessment based on Acceptable Daily Intake (ADI) of Pesticide Residues in Cabbage, Lettuce, Calyces and Tiger Nut from Markets in Gombe, Nigeria

\begin{tabular}{|c|c|c|c|c|c|c|c|c|c|c|}
\hline \multirow{2}{*}{$\begin{array}{l}0 \\
\stackrel{0}{0} \\
\stackrel{\Xi}{\infty}\end{array}$} & \multirow{2}{*}{ Pesticides } & \multirow{2}{*}{ BW (kg) } & \multicolumn{2}{|l|}{ Cabbage } & \multicolumn{2}{|l|}{ Lettuce } & \multicolumn{2}{|l|}{ Calyces } & \multicolumn{2}{|l|}{ Tiger nut } \\
\hline & & & EDI & $\mathrm{HI}$ & EDI & $\mathrm{HI}$ & EDI & HI & EDI & $\mathrm{HI}$ \\
\hline & Aldrin & Children & $\begin{array}{l}\text { use } \\
1.04 \mathrm{E}-03\end{array}$ & $1.04 \mathrm{E}-02$ & $\begin{array}{l}4.46 \mathrm{E}-04 \\
\end{array}$ & 7.46E-03 & use & $5.00 \mathrm{E}-01$ & 3.39 & $3.39 \mathrm{E}-02$ \\
\hline$\underset{0}{0}$ & & Adults & $1.73 \mathrm{E}-04$ & $1.73 \mathrm{E}-03$ & $1.24 \mathrm{E}-04$ & $1.24 \mathrm{E}-04$ & $8.33 \mathrm{E}-03$ & $8.33 \mathrm{E}-02$ & $5.65 \mathrm{E}-04$ & $5.65 \mathrm{E}-03$ \\
\hline \multirow{4}{*}{\multicolumn{2}{|c|}{$\begin{array}{l}\text { Alpha BHC } \\
\text { Gamma BHC } \\
\text {. } \\
\text { t. }\end{array}$}} & Children & $1.14 \mathrm{E}-03$ & 7.60E-05 & $1.04 \mathrm{E}-03$ & $6.93 \mathrm{E}-05$ & 4.60E-02 & $3.06 \mathrm{E}-03$ & $5.94 \mathrm{E}-03$ & $3.96 \mathrm{E}-04$ \\
\hline & & Adults & $1.90 \mathrm{E}-04$ & $1.26 \mathrm{E}-05$ & $1.73 \mathrm{E}-04$ & $1.15 \mathrm{E}-05$ & $7.66 \mathrm{E}-03$ & $5.10 \mathrm{E}-04$ & $9.90 \mathrm{E}-04$ & $6.60 \mathrm{E}-05$ \\
\hline & & Children & \multirow{2}{*}{ NC } & \multirow{2}{*}{$\mathrm{NC}$} & 1.64E-04 & 1.09E-05 & \multirow{2}{*}{ NC } & \multirow{2}{*}{$\mathrm{NC}$} & \multirow{2}{*}{$\mathrm{NC}$} & \multirow{2}{*}{$\mathrm{NC}$} \\
\hline & & Adults & & & $2.74 \mathrm{E}-05$ & $1.82 \mathrm{E}-06$ & & & & \\
\hline & \multirow[t]{2}{*}{ Dieldrin } & Children & $1.28 \mathrm{E}-03$ & $1.28 \mathrm{E}-02$ & 7.74E-04 & $7.74 \mathrm{E}-03$ & $5.95 \mathrm{E}-02$ & $5.95 \mathrm{E}-02$ & 2.91E-03 & $2.91 \mathrm{E}-02$ \\
\hline & & Adults & 2.13E-04 & 2.13E-03 & $1.29 \mathrm{E}-04$ & $1.29 \mathrm{E}-03$ & $9.91 \mathrm{E}-03$ & $9.91 \mathrm{E}-02$ & 4.84E-04 & 4.85E-03 \\
\hline & \multirow[t]{2}{*}{ Endosulfan I } & Children & 6.37E-04 & 1.06E-04 & $1.17 \mathrm{E}-04$ & $6.95 \mathrm{E}-05$ & $3.25 \mathrm{E}-02$ & $5.91 \mathrm{E}-02$ & $1.95 \mathrm{E}-03$ & $3.25 \mathrm{E}-04$ \\
\hline & & Adults & $1.06 \mathrm{E}-04$ & $1.73 \mathrm{E}-05$ & $6.96 \mathrm{E}-05$ & $1.16 \mathrm{E}-05$ & $5.41 \mathrm{E}-03$ & $9.01 \mathrm{E}-04$ & $3.25 \mathrm{E}-04$ & $5.41 \mathrm{E}-05$ \\
\hline & \multirow[t]{2}{*}{ Endosulfan II } & Children & $4.11 \mathrm{E}-04$ & 7.64E-05 & $3.35 \mathrm{E}-04$ & 6.39E-05 & $2.00 \mathrm{E}-02$ & $4.83 \mathrm{E}-03$ & $1.62 \mathrm{E}-03$ & 3.15E-04 \\
\hline & & Adults & $6.85 \mathrm{E}-05$ & $1.27 \mathrm{E}-05$ & $5.59 \mathrm{E}-05$ & $1.06 \mathrm{E}-05$ & 3.33E-03 & $8.05 \mathrm{E}-04$ & $2.70 \mathrm{E}-04$ & 5.25E-05 \\
\hline & \multirow[t]{2}{*}{ Endosulfan sulphate } & Children & 4.58E-04 & $6.85 \mathrm{E}-05$ & $3.38 \mathrm{E}-04$ & $5.59 \mathrm{E}-05$ & $2.90 \mathrm{E}-02$ & $3.33 \mathrm{E}-03$ & $1.89 \mathrm{E}-03$ & $2.70 \mathrm{E}-04$ \\
\hline & & Adults & 7.64E-05 & $1.14 \mathrm{E}-05$ & $6.39 \mathrm{E}-05$ & $9.31 \mathrm{E}-06$ & $4.83 \mathrm{E}-03$ & $5.55 \mathrm{E}-04$ & 3.15E-04 & $4.80 \mathrm{E}-05$ \\
\hline & \multirow[t]{2}{*}{ Heptachlor } & Children & 4.04E-05 & 8.08E-05 & $2.86 \mathrm{E}-04$ & $5.60 \mathrm{E}-04$ & $1.25 \mathrm{E}-02$ & $2.50 \mathrm{E}-02$ & $1.14 \mathrm{E}-03$ & $2.28 \mathrm{E}-03$ \\
\hline & & Adults & 6.73E-05 & $1.34 \mathrm{E}-04$ & 4.68E-04 & $9.36 \mathrm{E}-04$ & $2.08 \mathrm{E}-03$ & $4.16 \mathrm{E}-03$ & $1.90 \mathrm{E}-04$ & $3.80 \mathrm{E}-04$ \\
\hline & \multirow[t]{2}{*}{ Heptachlor expoxide } & Children & \multirow{2}{*}{$\mathrm{NC}$} & \multirow{2}{*}{$\mathrm{NC}$} & \multirow{2}{*}{$\mathrm{NC}$} & $\mathrm{NC}$ & $2.20 \mathrm{E}-02$ & $5.00 \mathrm{E}-02$ & $1.68 \mathrm{E}-03$ & $3.36 \mathrm{E}-03$ \\
\hline & & Adults & & & & (1) & $4.16 \mathrm{E}-03$ & $8.32 \mathrm{E}-03$ & $2.80 \mathrm{E}-04$ & $5.60 \mathrm{E}-04$ \\
\hline & Chlorpyriphos & Children & $5.82 \mathrm{E}-04$ & 5.82E-05 & $3.76 \mathrm{E}-04$ & 3.67E-05 & $1.44 \mathrm{E}-02$ & $1.45 \mathrm{E}-03$ & $1.47 \mathrm{E}-03$ & $1.47 \mathrm{E}-04$ \\
\hline$\stackrel{P}{0}$ & & Adults & $9.70 \mathrm{E}-05$ & $9.70 \mathrm{E}-06$ & $6.27 \mathrm{E}-05$ & $6.27 \mathrm{E}-05$ & $2.41 \mathrm{E}-03$ & $2.41 \mathrm{E}-04$ & 2.45E-04 & 2.45E-04 \\
\hline है & Diazinon & Children & $\mathrm{NC}$ & $\mathrm{NC}$ & $1.78 \mathrm{E}-04$ & $1.78 \mathrm{E}-04$ & $1.25 \mathrm{E}-02$ & $1.25 \mathrm{E}-02$ & $1.26 \mathrm{E}-03$ & $1.26 \mathrm{E}-03$ \\
\hline$\vec{\sigma}$ & & Adults & ive & 1 e & 2.96E-05 & $2.96 \mathrm{E}-05$ & 4.16E-03 & 4.16E-03 & 2.10E-04 & $2.10 \mathrm{E}-04$ \\
\hline 莺 & Dichlorovos & Children & 4.04E-04 & 2.02E-05 & 3.15E-04 & $1.57 \mathrm{E}-05$ & $1.50 \mathrm{E}-02$ & $7.50 \mathrm{E}-04$ & $\mathrm{NC}$ & $\mathrm{NC}$ \\
\hline $\overrightarrow{\&}$ & & Adults & $6.73 \mathrm{E}-05$ & 3.36E-06 & $5.25 \mathrm{E}-05$ & 2.62E-06 & $2.50 \mathrm{E}-03$ & $1.25 \mathrm{E}-04$ & & \\
\hline & Fenitrothion & Children & $3.42 \mathrm{E}-04$ & $5.70 \mathrm{E}-05$ & 3.69E-04 & $3.83 \mathrm{E}-05$ & $2.30 \mathrm{E}-02$ & $3.83 \mathrm{E}-03$ & 1.92E-03 & $3.20 \mathrm{E}-04$ \\
\hline & & Adults & $5.70 \mathrm{E}-05$ & $9.50 \mathrm{E}-06$ & 6.16E-05 & $6.38 \mathrm{E}-05$ & $3.83 \mathrm{E}-03$ & $6.38 \mathrm{E}-04$ & $3.20 \mathrm{E}-04$ & 5.33E-05 \\
\hline & Malathion & Children & $1.78 \mathrm{E}-04$ & $8.90 \mathrm{E}-06$ & $2.53 \mathrm{E}-04$ & $9.50 \mathrm{E}-04$ & $1.90 \mathrm{E}-02$ & $9.50 \mathrm{E}-04$ & $1.40 \mathrm{E}-03$ & $7.00 \mathrm{E}-05$ \\
\hline & & Adults & 2.96E-05 & 1.48E-06 & 4.22E-05 & $1.58 \mathrm{E}-04$ & $3.16 \mathrm{E}-03$ & $1.58 \mathrm{E}-04$ & 2.40E-04 & $1.20 \mathrm{E}-05$ \\
\hline & & Children & 4.58E-04 & 4.58E-05 & $2.12 \mathrm{E}-04$ & 2.19E-05 & $2.00 \mathrm{E}-02$ & $2.00 \mathrm{E}-03$ & $9.90 \mathrm{E}-04$ & $9.90 \mathrm{E}-05$ \\
\hline$\underset{0}{2}$ & Bifenthrin & Adults & 7.64E-05 & 7.64E-06 & $3.65 \mathrm{E}-05$ & $3.65 \mathrm{E}-06$ & 3.33E-03 & 3.33E-04 & $1.65 \mathrm{E}-04$ & $1.65 \mathrm{E}-05$ \\
\hline . & & Children & & & 2.67E-04 & $1.33 \mathrm{E}-05$ & $1.75 \mathrm{E}-02$ & $8.75 \mathrm{E}-04$ & $1.14 \mathrm{E}-03$ & $5.76 \mathrm{E}-05$ \\
\hline & Cypermethrin & & $\mathrm{NC}$ & $\mathrm{NC}$ & & & & & & \\
\hline & & Adults & & & 4.45E-05 & $2.22 \mathrm{E}-06$ & $2.91 \mathrm{E}-03$ & $1.45 \mathrm{E}-04$ & $1.90 \mathrm{E}-04$ & $9.50 \mathrm{E}-06$ \\
\hline & Deltamethrin & Children & 2.46E-04 & $2.46 \mathrm{E}-05$ & 4.65E-04 & 4.65E-05 & 1.10E-02 & $1.10 \mathrm{E}-03$ & $9.00 \mathrm{E}-04$ & $9.00 \mathrm{E}-05$ \\
\hline & 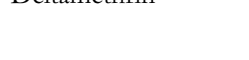 & Adults & 4.11E-05 & 4.11E-06 & 7.76E-05 & 7.76E-06 & $1.83 \mathrm{E}-03$ & $1.83 \mathrm{E}-04$ & $1.50 \mathrm{E}-04$ & $1.50 \mathrm{E}-05$ \\
\hline & & Children & $3.15 \mathrm{E}-04$ & $6.30 \mathrm{E}-06$ & $2.05 \mathrm{E}-04$ & 4.10E-06 & $2.40 \mathrm{E}-02$ & $4.80 \mathrm{E}-04$ & $7.80 \mathrm{E}-04$ & $1.56 \mathrm{E}-05$ \\
\hline & Permethrin & Adults & $5.25 \mathrm{E}-05$ & $1.05 \mathrm{E}-06$ & $3.42 \mathrm{E}-05$ & $6.84 \mathrm{E}-07$ & $4.00 \mathrm{E}-03$ & $8.00 \mathrm{E}-05$ & $1.30 \mathrm{E}-04$ & $2.60 \mathrm{E}-06$ \\
\hline
\end{tabular}

$\mathrm{NC}=$ Not calculated 


\section{CONCLUSION}

The study determined the presence of OCs, OPs and PYs residues in cabbage, lettuce, calyces and tiger nut from markets in Gombe, Nigeria. The results indicate that residual contents of pesticides ranged from 0.00 to $0.098 \mu \mathrm{g} / \mathrm{kg}, 0.00$ to 0.043 $\mu \mathrm{g} / \mathrm{kg}$ and 0.00 to $0.046 \mu \mathrm{g} / \mathrm{kg}$ with percentage of $62.55 \%, 21.60 \% 15.80 \%$ for OCs, OPs and PYs respectively. The estimated daily intakes of residues were lower than that of acceptable daily intakes. The hazard index of organochloride residues ranged from $5.00 \mathrm{E}-01$ to $7.64 \mathrm{E}-05$ for children and $9.91 \mathrm{E}-02$ to $9.31 \mathrm{E}-06$ for adults. The values for organophosphates are: $2.30 \mathrm{E}-02$ to $8.90 \mathrm{E}-06$ for children and 4.16E-03 to $9.70 \mathrm{E}-06$ for adults and for pyrethroids, the values are: 2.40E-02 to $9.90 \mathrm{E}-05$ for children and $6.84 \mathrm{E}-07$ for adults. The highest health index was found in OCs for aldrin ((5.00E-01) in calyces for children). The health risk assessment performed on OCPs OPs and PYs residues revealed that hazard index was less than one in all samples for both children and adults. However, strict regulation should be imposed regarding the usage of pesticides in vegetables and other food stuff for public health protection.

\section{Declaration of Competing Interest}

The authors declare that no conflicts of interest exist.

\section{REFERENCES}

Adeleye, A.O., Sosan, M.B., Oyekunle, J.A.O. 2019. Dietary exposure assessment of organochlorine pesticides in two commonly grown leafy vegetables in South-western Nigeria. Heliyon, 5:e01895. doi.org/10.1016/j.heliyon.2019.e01895

Ahoudi, H., Gnandi, K., Tanouayi, G., Ourosama, K., Yorke, J.C., Creppy, E.E., Moesch, C. 2018. Assessment of pesticides residues contents in the vegetables cultivated in urban area of Lome (southern Togo) and their risks on public health and the environment, Togo. International Journal of Biological and Chemical Sciences, 12(5): 2172-2185.

Angioni, A., Dedola, F., Garau, A., Sarais, G., Cabras, P., Caboni, P. 2011. Chlorpyrifos residues levels in fruits and vegetables after field treatment. Journal of
Environmental Science and Health, 46(6): 544549.

Charan, P.D., Ali, S.F., Yati, K., Sharma, K. 2010. Monitoring of pesticide residues in farmgate vegetables of central Aravalli region of Western India. AmericanEurasian Journal of Agricultural \& Environmental Sciences, 7(3): 255-258.

Chen, C., Qian, Y., Chen, Q., Tao, C., Li, C., Li, Y. 2011. Evaluation of pesticide residuesin fruits and vegetables from Xiamen, China. Food Control, 22(7): 1114-1120

Donkor, A., Osei-Fosu, P., Dubey, B., KingsfordAdaboh, R., Ziwu, C., Asante, I. 2016. Pesticide residues in fruits and vegetables in Ghana: a review. Environmental Science and Pollution Research International, 23(19): 18966-87.

EU, 2012. European Union. pesticide database, pesticide residues MRLs, Directorate General for Health \& Consumers, European Union, City of Brussels, Belgium.

Ftsum, G., Abraha, G. 2018. Health risk assessment of heavy metals via consumption of spinach vegetable grown in Elalla river. Bulletin of the Chemical Society of Ethiopia, 32(1): 65-75.

Grosso, G., Yang, J., Marventano, S., Micek, A., Galvano, F., Kales, SN. 2015. Nut consumption on all-cause, cardiovascular, and cancer mortality risk: a systematic review and meta-analysis of epidemiologic studies. American Journal of Clinical Nutrition, 101: 783-793.

Guler, G.O., Cakmak,Y.S., Dagli. Z., Aktumsek, A., Ozparlak, H. 2010. Organochlorine pesticide residues in wheat from Konya region, Turkey. Food and Chemical Toxicology, 48:1218-1221.

Han, Y., Mo, R., Yuan, X., Zhong, D., Tang, F., Ye, C., Liu, Y. 2017. Pesticide residues in nutplanted soils of China and their relationship between nut/soil, $C \quad b \quad e \quad m \quad o \quad s \quad p \quad b \quad e \quad r \quad e$, doi:10.1016/j.cheosphere.2017.03.138.

Jara, E.A., Winter, C.K. 2019. Safety levels for organophosphate pesticide residues on fruits, vegetables, and nuts. International Journal of Food Contamination, 6(6): 1-8.

Kumari, D., John, S. (2019). Health risk 
assessment of pesticide residues in fruits and vegetables from farms and markets of Western Indian Himalayan Region, Chemosphere, d o i : 10.1016/j.chemosphere.2019.02.091

Lehmann, E., Turrero, N., Kolia, M., Konaté, Y., De Alencastro, L.F. 2017. Dietary risk assessment of pesticides from vegetables and drinking water in gardening areas in Burkina Faso. Science of the Total Environment, 601:1208-1216.

Liu, Y., Shen, D., Li, S., Ni, Z., Ding, M., Ye, C., Tang, F. 2016. Residue levels and risk assessment of pesticides in nuts of China. Chemosphere, 144: 645-651..

Lozowicka, B., Abzeitova, E., Sagitov, A. 2015. Studies of pesticide residues in tomatoes and cucumbers from Kazakhstan and the associated health risks. Environmental Monitoring and Assessment, 187(10):4818. DOI: $10.1007 /$ s10661-015-4818-6

Ononamadu, C.J, Barau, M.M., Salawu, K., Ihegboro, G.O., Owolarafe, T.A., Lawal, A.T., Oshobu, M.L., Unah, P.E. 2019. Screening of selected vegetables from Wudil, farmlands in Kano State, Nigeria for organophosphorus and organochlorine pesticide residues. Journal of Environmental and Occupational Science, $8(2): 20-25$.

Ovaskainen. M.L., T“”orr" onen, R., Koponen, J.M. 2008. Dietary intake and major food sources of polyphenols in Finnish adults. Journal of Nutrition, 138(3): 562-566.

Oyeyiola, A.O., Fatunsin, O.T., Akanbi, L.M., Fadahunsi, D.E., Moshood, M.O. 2017. Human health risk of organochlorine pesticides in foods grown in Nigeria. Journal of Health \& Pollution, 15: 63-70.

Sapbamrer, R., Hongsibsong, S. 2014. Organophosphorus pesticide residues in vegetables from farms, markets, and a supermarket around Kwan Phayao Lake of Northern Thailand. Archives of Environmental Contamination and Toxicology, 67(1): 60-67.

Seyedeh, F.T., Hasan, B., Hayes, A.W., John, P.G., Gholamreza, K. 2019. Residues levels of pesticides in walnuts of Iran and associated health risks. Journal Human and Ecological Risk Assessment, DOI:

\subsection{0/10807039.2019.1704619}

Shakhaoat, H., Alamgir, H., Abdur, R., Mainul, I., Atiqur, R., Tanveer, M.A. 2013. Health risk assessment of pesticide residues via dietary intake of market vegetables from Dhaka, Bangladesh. Foods, 2:350-357.

Shoiful, A., Fujita, H., Watanabe, I. 2013.Concentrations of organochlorine pesticides (OCPs) residues in foodstuffs collected from traditional markets in Indonesia. Chemosphere, 90:1742-1750.

Silipunyo, T., Hongsibsong, S., Phalaraksh, C., Laoyang, S., Kerdnoi, T., Patarasiriwong, V., Prapamontol, T. 2016. Determination of organophosphate pesticides residues in fruits, vegetables and health risk assessment among consumers in Chiang Mai Province, Northern Thailand. Research Journal of Environmental Toxicology, 11(1):20-27.

Sinha, S.N., Rao, M.V.V., Vasudev, K. 2012. Distribution of pesticides in different commonly used vegetables from Hyderabad, India. Food Research International, 45(1): 161-169.

Sulaiman, M.B., Maigari, A.U. 2016. Physicochemical properties and heavy metals content of groundwater around a municipal dumpsite in Gombe, Nigeria. International Journal of Science and Research, 5(8):1299-1304.

Sulaiman, M.B,, Maigari, I.A., Yahaya, Y. 2019. Health risk assessment of heavy metals accumulation in tomatoes irrigation farms at Kwadon, Gombe, Nigeria. ATBU Journal of Science, Technology and Education, $7(2): 271-280$.

Swarnam, T.P., Velmurugan, A. 2013. Pesticide residues in vegetable samples from the Andaman Islands, India. Environmental Monitoring and Assessment, 185(7): 61196127.

USEPA, 1989. Exposure assessment handbook. United States Environmental Protection Agency. Office of Health and Environmental Assessment, Washington, D. C.

USEPA, 1996. Integrated risk information system. United States Environmental Protection Agency. Office of Health and Environmental Assessment, Washington, 
D. C.

Vincent, K.B., Nathaniel, O.B., Lawrence, S.B., Samuel, A. 2018. Human risk assessment of organochlorine pesticide residues in vegetables from Kumasi, Ghana. Journal of Chemistry, doi.org/10.1155/ 2018/3269065.

Wang, H.S., Sthiannopkao, S., Du, J. 2011. Daily intake and human risk assessment of organochlorine pesticides (OCPs) based on Cambodian market basket data. Journal of Hazardous Materials, 192(3): 1441-1449.

WHO, 1990. (World Health Organization in collaboration with UNEP). Public Health
Impact of Pesticides Used in Agriculture; WHO: Geneva, Switzerland, 1-129.

Yang, T., Liu, J. 2012. Health risk assessment and spatial distribution characteristic on heavy metals pollution of Haihe river basin. Journal of Environmental and Analytical Toxicology, 2:152. doi: 10.4172/21610525.1000152.

Yasir, M., Muhammad, A., Harald, K., Nasir, M., Rong, K. 2020. Pesticide residues, health risks, and vegetable farmers' risk perceptions in Punjab, Pakistan. Journal Human and Ecological Risk Assessment, doi: 10.1080/10807039.2020.1776591. 